\title{
Contracampo
}

\section{Espetáculos do medo: o horror como atração no cinema japonês}

\author{
Spectacles of fear: \\ The horror as attraction in Japanese Cinema
}

Laura Loguercio Cánepa

laurapoa@hotmail.com

Professora do Mestrado em Comunicação da Universidade Anhembi Morumbi.

Doutora em Multimeios, Unicamp.

Rogério Ferraraz

rogerioferraraz@uol.com.br

Professor e Coordenador do Mestrado em Comunicação da Universidade Anhembi Morumbi.

Doutor em Comunicação e Semiótica, PUC-SP.

Ao citar este artigo, utilize a seguinte referência bibliográfica

CÁNEPA, Laura Loguercio. FERRARAZ, Rogério. Espetáculos do medo: o horror como atração no cinema japonês. In: Revista Contracampo, n 25, dez. de 2012. Niterói: Contracampo, 2012. Pags: 04-23.

Enviado em: 25 de set. de 2012 Aceito em: 14 de dez. de 2012

\section{PPGCOM}

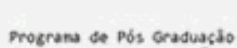

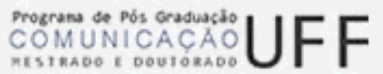

$$
\text { Edição 25/2012 }
$$

Ensaio temático "Mídia e Medo"

Contracampo

Niterói (RJ), n²5, dez/2012.

www.uff.br/contracampo

e-ISSN 2238-2577
A Revista Contracampo é uma revista eletrônica do Programa de Pós-Graduação em Comunicação da Universidade Federal Fluminense e tem como objetivo contribuir para a reflexão crítica em torno do campo midiático, atuando como espaço de circulação da pesquisa e do pensamento acadêmico. 


\section{Resumo}

Dentro da variada gama de filmes vindos da Ásia oriental, uma das mais influentes contribuições é a do cinema de horror desenvolvido no Japão a partir da segunda metade dos anos 1990, cuja inserção internacional fez com que, no Ocidente, fosse criado um "selo" para designá-lo: o "J-Horror". Porém, o alcance dessa produção vai muito além de um simples selo ou abreviatura. Este artigo pretende traçar algumas reflexões sobre o horror cinematográfico contemporâneo a partir da experiência japonesa, colocando em destaque o caráter espetacular e de atração do gênero, notório nessa produção enraizada em tradições teatrais. Como objeto específico para a discussão, o texto se concentra em um subgênero tradicional do horror japonês, o do "espírito vingativo" (onryou), que deu origem ao mais famoso exemplar do J-horror no Ocidente: Ringu O Chamado (Ringu, Hideo Nakata, 1998).

Palavras-chave: Cinema, teatro, atração, horror, Japão.

\section{Abstract}

Within the wide range of films from East Asia, one of the most influential contributions is that of horror cinema developed in Japan since the second half of the 1990s, whose international integration led to the creation of a "seal": "J-Horror". However, the scope of this production goes far beyond a simple seal or abbreviation. This article seeks to draw some reflections on the contemporary horror film from the Japanese experience, highlighting the spectacular character of this notable production rooted in theatrical traditions. The specific object for discussion is a traditional horror subgenre Japanese of the "vengeful spirit" (onryou), which led to the most famous japanese movie in the West: The Ring (Ringu, Hideo Nakata, 1998).

Keywords: Cinema, theatre, attraction, horror, Japan. 
$\mathrm{O}$ horror cinematográfico concebido como gênero da indústria teve seu momento inaugural nos estúdios da Universal, produtora dedicada majoritariamente ao cinema de segunda linha em Hollywood, no começo dos anos 1930, com o sucesso dos filmes Dracula (Tod Browning, 1931) e Frankenstein (James Whale, 1931) - em parte inspirados pelo impacto de produções alemãs que com alguma frequência haviam abordado histórias de horror em obras de fama internacional como $O$ Gabinete do Dr. Caligari (Das Cabinet der Dr. Caligari, Robert Wiene, 1919) e Fausto (Faust, F.W. Murnau, 1926). Também contribuíram para o ciclo de filmes de horror dos anos 1930 algumas montagens teatrais de textos clássicos do gênero, em particular Dracula: The Vampire Play ${ }^{I}$, encenada na Broadway com direção de Horace Liveright, em 1927. A peça foi tão popular que acabou por consagrar seu ator principal, o húngaro Bela Lugosi, no papel de Conde Drácula, da mesma forma que Edward Van Sloan, como seu perseguidor Van Helsing, no clássico cinematográfico de 1931.

Ao longo das três décadas seguintes, as produções hollywoodianas foram dominantes no gênero, mesmo contando com baixo status e pequenos orçamentos. Porém, no final dos anos 1950, outros países começaram a apresentar ciclos próprios de produção de horror, principalmente o Japão (com os filmes de monstros gigantes e de fantasmas dos estúdios Toho, Daiei e Shintoho ${ }^{2}$ ), a Inglaterra (com a retomada dos monstros clássicos pela produtora $\mathrm{Hammer}^{3}$ ), a Itália (com as produções de segunda linha de Ricardo Fredda e Mario Bava ${ }^{4}$ ) e o México (que, além de produzir dezenas de filmes, abrigou atores famosos do horror em fim de carreira ${ }^{5}$ ).

Tais ciclos nacionais não chegaram a ameaçar a hegemonia da indústria estadunidense, que se manteve à frente com produções baratas e depois inaugurou os lançamentos de primeira linha do gênero a partir do final dos anos 1960, com os

\footnotetext{
${ }^{1}$ Escrita por Hamilton Deane, na Inglaterra, em 1924, com base no romance de Bram Stocker, publicado em 1897. Reescrita para a montagem estadunidense por John Badelstorn, em 1927.

${ }^{2}$ O filme mais famoso desse ciclo foi Godzilla (Gojira, Ishiro Honda, 1954), que deu origem a uma série de 28 filmes da produtora Toho, além de histórias em quadrinhos, desenhos animados e séries de TV.

${ }^{3}$ A produtora lançou, em 1957, A Maldição de Frankenstein (The Curse of Frankenstein, de Terence Fisher). Com o sucesso internacional, passou a explorar filmes de horror relativamente baratos que mantiveram a produtora ativa até 1979 e consagraram os atores Christopher Lee e Peter Cushing.

${ }^{4}$ Que daria origem a uma geração de seguidores na década seguinte, com nomes de fama mundial como Dario Argento (Suspiria, 1977) e Lucio Fulci (Zombi 2, 1979).

${ }^{5}$ Boris Karloff, por exemplo, atuou em quatro filmes de horror mexicanos, no final dos anos 1960, pouco antes de morrer, em 1969.
} 
sucessos mundiais de O Bebê de Rosemary (Rosemary's Baby, Roman Polanski, 1968, adaptado do best seller homônimo de Ira Levin, 1967) e O Exorcista (The Exorcist, William Friedkin, 1973, adaptado do romance de William Peter Blatty, 1971) mantendo a liderança comercial ainda hoje na maior parte do planeta. Porém, como observa Collete Balmain (2008: ix), nos últimos vinte anos, o cinema hollywoodiano de horror tem revelado uma notória crise de criatividade, o que faz com que não se canse de apresentar inúmeros remakes de obras de sucesso, além de infinitas continuações de séries, entre elas Pânico (Scream, Wes Craven, 1996, 1997, 2000, 2011), Premonição (Final destination, Vários diretores, 2000, 2003, 2006, 2009, 2011) e Jogos Mortais (Saw, Vários diretores, 2005, 2006, 2007, 2008, 2009, 2010, 2011).

Nesse processo, um fenômeno que colocou Hollywood em alerta foi o chamado $J$ horror, codinome que ganharam os filmes de horror japoneses lançados nos anos 1990/2000, cuja fama mundial começou com o sucesso de Ringu - O Chamado (Ringu, Hideo Nakata, 1998) e foi seguida por crescente interesse internacional, reabrindo caminhos para o horror asiático além das fronteiras do Japão, com uma importante leva de filmes vindos também da Coréia do Sul, de Hong Kong e da Tailândia. O impacto foi significativo a ponto de distribuidoras hollywoodianas terem se encarregado da circulação dos filmes fora do Japão ${ }^{6}$, e de remakes feitos nos EUA superarem, dentro do Japão, as bilheterias dos originais nacionais. Como relata Kalat (2007: 240), por exemplo, o original Ringu, de Nakata, arrecadou 6,6 milhões de dólares nas bilheterias domésticas, em 1998. Já O chamado (The Ring), o remake hollywoodiano de Gore Verbinski, arrecadou no Japão, em 2002, mais de 8,3 milhões de dólares apenas nas duas primeiras semanas em cartaz - o que ilustra bem a dinâmica de mútua fertilização entre essas duas cinematografias.

Sem a pretensão de historicizar o processo que deu tamanha visibilidade ao horror asiático na virada do milênio, este artigo tem o objetivo de apontar e discutir alguns aspectos do J-horror que contribuíram tanto para a diversificação da produção contemporânea do gênero quanto para o próprio pensamento sobre o cinema de horror nos últimos anos. Para isso, pretendemos destacar particularmente aspectos específicos

\footnotetext{
${ }^{6}$ Bailman (2008: ix) destaca o fato da distribuidora Lionsgate, uma das maiores do mundo no gênero horror, ter se encarregado, desde 2004, da distribuição internacional dos filmes de horror da companhia japonesa Toho.
} 
relacionados ao caráter espetacular e "atracional" do gênero, notórios nessa produção que, como veremos, está profundamente enraizada em tradições teatrais.

\section{O horror cinematográfico pensado como espetáculo}

Entendido como produto de um gênero predominantemente narrativo voltado a suscitar experiências de medo e repugnância em seus espectadores, o horror artístico (CARROLL, 1999: 27) ${ }^{7}$, quer se manifeste numa obra poética, teatral ou audiovisual, é um fenômeno estético difícil de definir. Essa "emoção polimorfa" (LAURENT; GUIDO, 2010: 07) é provocada por um dispositivo simbólico particular em que o espectador se vê diante de uma situação ficcional na qual os personagens estão ameaçados por forças letais cuja existência lhes é incompreensível. Esse sentimento de medo e perplexidade buscado pelas obras de horror pode ser "ativado" de diversas maneiras, o que ajuda a explicar a variedade de possibilidades de expressão do gênero em diferentes formas narrativas. E, nesse sentido, as obras também se distinguem umas das outras pelos aparatos técnicos expressivos específicos de diferentes meios, como o literário, o teatral, o audiovisual etc.

No caso do horror cinematográfico, esse vem suscitando um interesse crescente nas últimas quatro décadas, sendo analisado sob diferentes perspectivas, entre as quais suas representações sociopolíticas (em trabalhos pioneiros como os de Robin Wood e Richard Lipp, em 1979, e mais tarde de Reynold Humphryes, em 2000), hibridações genéricas (como analisam Mark Jankovitch, 2002; Steve Neale, 1999), aspectos mitológicos, pulsionais e cognitivos (Gerard Lenne, 1974; Jack Morgan, 2002; Noel Carroll, 1999, respectivamente), questões de representação e de políticas de gênero (Carol Clover, 1992; Linda Williams, 2000), análises culturalistas (Jeffrey Sconce, 2000), entre outras.

Mas, como observam Laurent Guido e Richard Bégin (2010: 08), até recentemente, pouco interesse teórico houve sobre o aspecto espetacular dos dispositivos do horror no cinema, como a fantasmagoria e o melodrama cênico, por exemplo. De acordo com os autores, tais abordagens podem ser bastante frutíferas, pois

\footnotetext{
${ }^{7}$ Segundo Carroll, a noção de horror artístico "pretende referir-se ao produto de um gênero específico que se cristalizou (...) e que persistiu, não raro ciclicamente, através de peças e romances do século XIX e da literatura, dos quadrinhos, das revistas e dos filmes no século XX.” (1999: 27).
} 
uma qualidade que emerge do gênero horror é uma ideia muito cara ao cinema desde suas origens, a da mostração (GAUDREAULT, 1984), não ligada exclusivamente às tradições narrativas, mas também às espetaculares, circenses e teatrais. Na lógica exibicionista da mostração, o filme de horror buscaria suscitar o efeito de um sentimento de confrontação imediata (ou mediada por um ponto de vista irremediavelmente envolvido na ação) com a violência na experiência audiovisual (BÉGIN; GUIDO, 2010: 09).

Seguindo uma linha bem próxima, Robert Spadoni (2010: 68), escudado pela discussão do cinema de atrações (GUNNING, 1986), procura revisar a noção corrente de que essa concentração nos momentos de violência episódica enfraqueceria a unidade formal dos filmes de horror. De acordo com ele, é comum que as análises dessas obras critiquem sua preferência por confrontar o espectador com dispositivos exibicionistas mais do que por levá-los a universos narrativos autossuficientes (Ibid, 66). Mas, como observa Spadoni, a lógica das atrações, tão presente no cinema das origens, não desapareceu durante o processo de integração narrativa do cinema clássico. Citando Gunning, o autor argumenta que os "fragmentos livres de atrações foram integrados ao cinema narrativo, deixando de ser independentes" (Id, Ibid) - e, nesse sentido, o filme de horror é, para ele, um bom exemplo de cinema contemporâneo que preserva a dinâmica das atrações.

A contribuição dos pesquisadores Guido, Bégin e Spadoni à discussão sobre o horror cinematográfico chama a atenção para o fato de que, apesar das características compartilhadas pelo gênero em diferentes meios de expressão, há especificidades que precisam ser levadas em conta. Na mesma linha de pensamento, afirma Powell:

\begin{abstract}
A trama do filme de horror, sua ação, seus efeitos especiais e, finalmente, a existência do filme em si, são tecnologicamentedependentes. Os eventos são registrados, vistos e ouvidos através de lentes de câmeras e microfones, e estão sendo devolvidos para nós por meio de cine-projetores e DVD players. O espectador experimenta um desses filmes também como um evento. Câmera, foco borrado e closeups extremos, além de recursos mais extravagantes, como imagens geradas por computador (CGI), têm um efeito direto sobre os nossos mecanismos de percepção antes de atingir um estágio mais avançado de processamento cognitivo. (POWELL, 2005, p. 05, Tradução nossa) ${ }^{8}$.
\end{abstract}

\footnotetext{
${ }^{8}$ No original: "The horror film's plot, action, special effects and, finally, the existence of the film itself, is technology-dependent. Events are recorded, seen and heard through camera lenses and microphones, as
} 
Exemplo do tipo de discussão que as abordagens através das atrações e da mostração cênica podem trazer é o trabalho de Guido (2010), que se dedica a investigar a teatralidade do horror no cinema a partir de suas origens cênicas como atrações espetaculares na fantasmagoria e no melodrama. Para ele, toda a história do cinema de horror está emoldurada por uma referência reflexiva à mostração cênica, e inúmeros motivos e procedimentos do cinema de horror têm origem numa vasta cultura teatral nem sempre levada em consideração pelos estudiosos do gênero (2010: p. 13; 15).

Mas, ainda que uma parte do cinema de horror ocidental demonstre consciência dessa "teatralidade", percebida nos já mencionados filmes inaugurais de horror da Universal, e também, por exemplo, no estilo Grand Guignol ${ }^{9}$ do horror italiano dos anos $1970^{10}$, acreditamos que o cinema japonês pode trazer contribuições à discussão iniciada por esses autores. Pois, como mostra Bailman (2008: 12), uma característica central dessa cinematografia em geral - e que tem um impacto no horror em particular - é a relação intensa da indústria de cinema nipônica, desde o seu início, com as mais proeminentes produções teatrais nacionais. E isso não só no que diz respeito aos temas abordados nos filmes, mas também ao aproveitamento de técnicos, de artistas e do próprio estilo de representação, inspirado em alguns elementos dos teatros Nô e, principalmente, do Kabuki (Id. Ibid).

O Kabuki é um tipo de espetáculo popular que surgiu no Japão do século XVII, quando passou a conviver com o Nô, forma tradicional do século XIV caracterizada pelo uso de máscaras e de grande estilização, consistindo numa fusão de ruídos, dança e música (HAND, 2005: 21). As peças Nô giram em torno de dois atores: o shite (quase sempre mascarado, com papéis variados que podem ser de uma mulher, de um velho, de um animal, de um fantasma ou de um demônio) que conta sua história ao waki (que sempre é do sexo masculino, nunca é mascarado e tem por função chamar o shite para o

well as being played back to us by cine-projectors, video and DVD players. The viewer also experiences the film as an event. Camera shake, blurred focus and extreme close-ups, as well as more flamboyant effects such as computer-generated-imagery (CGI) have a direct affect on our mechanisms of perception before they reach more advanced stage of cognitive process."

${ }^{9}$ Teatro francês fundado em 1897, no bairro de Pigalle, em Paris. Era dedicado a espetáculos de horror, geralmente divididos em episódios curtos que traziam cenas intensas de violência, com mutilações torturas, aparições fantasmagóricas. O Grand Guignol encerrou suas atividades em 1962 coincidentemente (ou não) quando o cinema de horror começava a se tornar mais explícito e a ser filmado a cores, sobretudo nos Estados Unidos, na Inglaterra e na Itália.

10 Em particular na obra de Dario Argento, com filmes de mortes espetaculares em série, entre os quais Suspiria, de 1977, e Terror na Ópera, de 1987. 
palco, questioná-lo e incentivá-lo a dançar). Uma performance Nô pode durar um dia inteiro e é composta de cinco peças selecionadas de cinco categorias que incluem, entre outras, o shuru-mono (recitado pelo fantasma de um guerreiro), o kyojo-mono (recitado por uma mulher louca) e o shunen-mono (recitado pelo fantasma vingador de uma mulher louca) (ARNAUD, 2010: 121). Já o Kabuki, mais espetacular e variado em sua temática e estrutura, é um amálgama das artes performáticas cujo nome é uma fusão das palavras Ka (música), Bu (dança) e Ki (atuação ou habilidade). (HAND, 2005: 21)

O Kabuki, diferentemente do Nô, não faz uso obrigatório das máscaras e tem maior preocupação com cenas de grande impacto. Por isso, dá ênfase a algumas habilidades bem específicas de atores e técnicos. Uma delas é a capacidade do ator de congelar-se em poses pitorescas que expressam as emoções das personagens. Essa prática, chamada de mie (que significa "visível"), consiste geralmente no enrijecimento dos braços e dos dedos, juntamente com o enviezamento e a abertura extrema dos olhos - que, na descrição de Handa (2012), "provocam uma impressão de força concentrada e precisa [que] pode até ser grotesca e sobre-humana, mas insere em si o eixo central da arte kabuki”. Para aqueles familiarizados com os filmes de horror japoneses, é fácil perceber a importância do mie na representação dos monstros e principalmente dos fantasmas, como se verifica, por exemplo, nas aparições do espírito de Sadako, de $O$ Chamado. Outro aspecto fundamental do Kabuki herdado pelo cinema é o conjunto de técnicas chamado de keren, que diz respeito aos efeitos especiais desenvolvidos para cenas de batalhas, torturas e outros momentos intensos do espetáculo (HAND, 2005: 23). Como relata Arnaud (2010: 123), um livro em quatro volumes publicado no Japão entre 1858 e 1859 dava conta de ilustrar 342 técnicas de keren, entre as quais a flutuação de fantasmas e movimentos de esqueletos.

Segundo Hand, o horror é motivo recorrente no Nô e no Kabuki, tanto nas histórias sobrenaturais quanto nas de extrema violência. E, para ele, "o cinema de horror japonês, pela forma de estruturar suas tramas, performances e iconografia, deve mais a esse teatro tradicional do que aos mecanismos do horror ocidental (2005: 22)." O caso exemplar apresentado pelo autor em sua análise dos aspectos teatrais do horror japonês é o da mais paradigmática peça kabuki de fantasma, Tokaido Yotsuya Kaidan (O Fantasma de Yotsuya), escrita em 1825 por Tsuruya Namboku, que foi adaptada onze 
vezes para o cinema, sendo a versão de Nobuo Nakagawa (Tokaido Yotsuya Kaidan ${ }^{11}$, 1959), a mais famosa.

A trama envolve um homem que envenena a esposa doente. Ela acaba morrendo totalmente deformada, mas retorna como fantasma e enlouquece o marido, fazendo com que ele mate a nova esposa e se suicide. De acordo com Hand (Ibid: 27), tanto no teatro quanto no cinema, são variadas e espetaculares as habilidades da esposa-fantasma: ela voa, deforma-se, pendura-se no teto, espalha seus longos cabelos negros por onde passa, surge dentro de lanternas - de maneira bastante semelhante ao que se dá em filmes de fantasmas japoneses contemporâneos, cujas personagens fantasmagóricas são quase sempre mulheres que morreram em condições extremamente injustas e violentas, e retornam do mundo dos mortos vestidas de branco (cor da vestimenta fúnebre no Japão) para vingar-se, com um ódio infinito.

Como afirma Hand, "embora a tragédia grega ou o teatro elisabetano sejam considerados quase sempre precursores de horror moderno, o teatro clássico japonês oferece também um modelo bastante desenvolvido para o cinema de horror contemporâneo" (2005: 27), trazendo uma iconografia sobrenatural que parece ter sido um sopro de novidade a partir do final dos anos 1990 em inúmeros filmes de sucesso, entre os quais Ringu, Pulse (Kairo, 2001, Kyioshi Kurosawa), O Grito (Ju-On, Takashi Shimizu, 2002), Água Negra (Honogurai mizu no soko kara, Hideo Nakata, 2002), Uma Chamada Perdida (Chakushin ari, Takashi Miike, 2003) - todos depois refeitos nos EUA com direção de Gore Verbinski (2002), Jim Sonzero (2006), Takashi Shimizu (2004), Walter Salles (2005) e Eric Valette (2008), respectivamente.

Evidentemente, porém, conforme observa McRoy (2005:15), sendo as narrativas de horror produtos da interação entre características textuais específicas e circunstâncias sociais distintas, o fato de temas e imagens tradicionais emergirem no cinema japonês atual não significa que esses tropos e motivos tenham se mantido estáticos em significação social e ressonância ideológica. Nesse caso, é preciso aprofundar a compreensão da configuração do J-horror nos anos 1990/2000, quando disseminou sua influência no cinema mundial, encontrando novas articulações e novas audiências, e legou ao cinema hegemônico um universo de figuras e situações horríficas cujo modo

\footnotetext{
${ }^{11}$ Não foram encontrados registros de lançamento no Brasil, nem título em português.
} 
de representação está relacionado também (mas não apenas) a procedimentos estilísticos do teatro tradicional japonês.

\section{Intercâmbios culturais}

Como observa Hand (2005: 18-19), uma das preocupações dominantes quando uma cultura não-ocidental é analisada pelos ocidentais diz respeito ao intercâmbio cultural. No que se refere às análises do cinema japonês, o autor destaca a atenção dada, por exemplo, a adaptações como a de Macbeth, feita por Akira Kurosawa no Japão (Trono Manchado de Sangue, 1954), ou à de John Sturges, nos EUA, de Os Sete Samurais (1957), do mesmo Kurosawa, chamada de Sete Homens e Um Destino (The Magnificent Seven, 1960) que foi um dos maiores sucessos do faroeste americano dos anos 1960, dando origem a três continuações.

Ainda que essa postura comparativa muitas vezes revele nossa dificuldade de observar uma cultura estrangeira, de fato, falar em cinema japonês exige que se pense com cuidado sobre os processos de assimilação cultural que se deram no país ao longo do século XX. Para Bailman (2008: ix), a capacidade de assimilação é fundamental para explicar a relação da cultura japonesa com o resto do mundo, e com o Ocidente em particular. Exemplo disso, no caso do cinema, é o desenvolvimento dos estúdios japoneses no século XX, bastante semelhante ao que se deu em Hollywood. Também as carreiras internacionais bem-sucedidas dos cineastas Kenji Mizoguchi (1898-1956) e Akira Kurosawa (1919-1998) a partir da década de 1950 dão conta da inventividade com que os modelos do cinema clássico ocidental foram absorvidos e devolvidos pelo cinema japonês, num processo de mútua fertilização que trouxe inovações em gêneros como o melodrama, o épico, o filme de guerra, o filme de samurai e o faroeste.

Igualmente, a forma pela qual o horror foi absorvido pelo cinema japonês a partir dos anos de ocupação americana no Pós-Guerra (de 1948 a 1952) ilustra bem o tipo de assimilação que lá ocorreu. Desde então, ele se tornou um componente vital da indústria do cinema japonês. Durante o período turbulento da reconstrução do Japão, Ishiro Honda, diretor do filme de monstro Godzilla (Gojira, 1954), Kaneto Shindo, do filme de mulher demoníaca Onibaba (1964), e Masaki Kobayashi, do filme de fantasmas Kwaidan (1964), entre outros, criaram filmes de horror influentes dentro e 
fora de seu país. Geralmente informados pelo folclore e em débito com a estética dos teatros Nô e Kabuki, esses filmes, como descreve McRoy (2005, p. 01), engajaram uma miríade de complexas ansiedades políticas, sociais e ecológicas, incluindo - mas não se restringindo - a apreensão sobre o impacto da cultura ocidental e do imperialismo militar sobre a identidade nacional japonesa.

Entre os subgêneros do horror surgidos no cinema japonês desde então, tem-se os já mencionados filmes de fantasmas (Kaidan-eiga) e de monstro (Daikaiju-eiga), além dos filmes de tortura (como Ichi the Killer, de Takashi Miike, 2001), os apocalípticos (como Battle Royale, de Kinji Fukasako, 2000) e os de horror tecnológico (como Tetsuo - The Iron Man, de Shin'ya Tsukamoto, 1989), todos frequentemente ligados também a tradições das artes visuais japonesas, em particular o mangá. Neste artigo, porém, quer-se tratar especificamente de um filme paradigmático de um desses subgêneros - o Kaidan-eiga - que inaugurou essa grande onda mundial do horror asiático: Ringu - O Chamado, dirigido por Hideo Nakata.

\section{O espírito vingativo, Ringu e a atração fantasma}

Recorrente nas artes dramáticas e literárias do Japão, o espírito vingativo, chamado de onryou, é uma das figuras centrais do horror japonês contemporâneo. Estruturado a partir de uma pluralidade de tradições religiosas que, segundo McRoy, inclui do shintoísmo ao cristianismo (2005: 175), além de ser motivo frequente no teatro tradicional, ele aparece em inúmeras narrativas que tratam da intrusão de um fantasma na vida ordinária em busca de vingança.

A mais conhecida dessas narrativas está no filme Ringu, lançado em 1998 e baseado no romance homônimo de Koji Suzuki (uma espécie de Stephen King do Japão $^{12}$ ) lançado em 1991. Nakata já adaptara o livro para a televisão em 1995, e, com o sucesso do telefilme entre os jovens japoneses, teve a oportunidade de levar a mesma história para a tela grande, num novo trabalho cujo resultado repercutiu bem por toda a Ásia, dando origem a uma série de cinema e outra de TV japonesa, além de um remake

\footnotetext{
12 Stephen King é o mais famoso autor de romances fantásticos e de horror nos Estados Unidos, quase todos adaptados para o cinema, como Carrie, publicado em 1974 e lançado nos cinemas em 1977 como Carrie - A Estranha (Carrie, Brian de Palma, 1977) e O Iluminado, publicado em 1977 e cuja adaptação foi lançada nos cinemas também com o mesmo título (Shining, Stanley Kubrick, 1989).
} 
dirigido por Gore Verbinski, produzido pela empresa estadunidense DreamWorks (de Steven Spielberg) quatro anos depois, e que arrecadou mais de 240 milhões de dólares nas bilheterias mundiais.

O enredo de Ringu traz a repórter de televisão Reiko Asakawa (Nanako Matsushima), que tem um filho pequeno, Yoichi (Rikiya Otaka), e que está fazendo uma matéria sobre uma lenda urbana a respeito de uma fita de vídeo que, quando vista, condena à morte seu espectador num prazo de sete dias. Ao ir ao velório de sua sobrinha que morreu misteriosamente - no rosto do cadáver, há uma expressão extremada de medo -, ela descobre que suas colegas atribuem a morte à tal maldição. Reiko encontra um recibo de revelação fotográfica deixado pela sobrinha em seu quarto e, ao retirar as fotos na loja, percebe que ela passou um fim de semana com amigos num chalé nas montanhas e que, a partir de um determinado momento, os rostos das pessoas nas fotos começaram a aparecer deformados. Ela descobre onde fica tal chalé e encontra a fita de vídeo. Logo após assistir à fita, ela recebe um telefonema e escuta um ruído assustador, demoníaco. Desesperada, pede ajuda a Ryuiji Takayama (Hiroyuki Sanada), um antigo namorado e pai de Yoichi. Ela faz uma cópia da fita para ele analisar. Os dois, então, vão juntos investigar a origem da fita e descobrem tratar-se de uma maldição elaborada pelo espírito de Sadako (Rie Ino'o), garota paranormal assassinada muitos anos antes por seu pai. Eles encontram o esqueleto de Sadako no poço em que a garota fora jogada ainda viva, e acreditam, assim, ter conseguido se livrar da maldição. Takayama, porém, morre sob as mesmas condições das outras vítimas, o que leva Reiko a compreender que a única forma de se salvar (e também ao filho, que assistira à fita) é fazendo uma cópia do vídeo e repassando-a para outra pessoa, num ciclo ininterrupto de revelação e ressentimento do espírito de Sadako.

Ao revisitar o mito do espírito vingador, o filme se inspira em inúmeras fontes que incluem o livro de Koji Suzuki, clássicos do cinema japonês (Tokaido Yotsuya Kaidan, em particular) e também a lenda de Okiku, transplantada para o teatro Kabuki na peça Banchô Sarayashiki, escrita por Okamoto Kido, em $1925^{13}$, em que uma jovem servente é assediada por seu patrão samurai e, ao recusar o assédio, acaba sendo atirada em um poço - para depois retornar como fantasma. Mas os traços do horror ocidental também são evidentes em Ringu. A presença de uma jornalista investigativa, figura

\footnotetext{
${ }^{13}$ Cf. ARNAUD, 2010: 122.
} 
comum nas histórias ocidentais de mistério, além da estrutura inicial que remete ao subgênero slasher (em que adolescentes são mortos em série numa ação de vingança interminável) atestam a presença de elementos importados. Para McRoy (2005, p. 175), observar as motivações desses espíritos vingativos da ficção japonesa pode prover valiosos insights sobre as tensões históricas, políticas e socioculturais dessa mistura de imagens nostálgicas em um país pós-industrial atravessado pelas tecnologias da comunicação e pela cultura midiática mundial.

Assim, são muitas as possibilidades de abordagem e interpretação de diversos aspectos da obra de Nakata. Para Christopher Sharrett:

Ainda que não especialmente irônico em relação ao fenômeno do capitalismo patriarcal, a sua representação é notória no horror japonês, como resultado de uma sociedade que ainda mantém residualmente suas tradições. O popular Ringu, que deve muito a fontes anteriores do fantástico japonês, retrata a colisão de mitos culturais tradicionais (muitos deles centrados numa hipócrita e exagerada veneração à mulher) com a perversa realização numa paisagem pós-industrial. (SHARRETT, 2005: xii, Tradução. nossa ${ }^{14}$ ).

Já para Erick Felinto, o filme é também um amálgama contemporâneo de questões que sempre cercaram a ficção fantástica e de horror:

[Ringu] $O$ Chamado constitui provavelmente a mais completa exploração cinematográfica do tema da fantasmagoria - pelo menos naquilo que poderíamos qualificar como sua abordagem contemporânea. Ele toca em praticamente todos os assuntos (...): o fantasma como duplo, o perigo do olhar, a comunicação por meio das imagens, o imaginário tecnológico das assombrações, a fantasmização do real. Mais que isso, em $O$ Chamado o fantasma é uma tecnologia comunicacional, um mecanismo para a propagação infindável de uma mensagem. Seu objetivo é expressar- se, e seu olhar fantasmagórico constitui o aparato veiculador da mensagem final: a visão mata, a imagem é uma ameaça a ser temida. (FELINTO, 2006: 23).

Mas, para além dessas abordagens e de outros aspectos da trama, uma cenachave de Ringu tornou-se paradigmática para o horror contemporâneo e também para a discussão em torno do caráter atracional desse tipo de ficção. Trata-se da aparição do espírito de Sadako para Takayama, quase no final do filme (Figs. 1 e 2).

\footnotetext{
${ }^{14}$ No original: "While there's nothing especially ironic about the phenomenon, Japanese horror cinema's graphic portrayal of patriarchal capitalism's rampage is especially compelling within a society that has held sacred some positive, now rather residual, traditions. Nakata's popular Ringu, which owes a great deal to earlier phases of the japanese fantastique, portrays the collision of traditional cultural myths (many centered on an exaggerated and hypocritical veneration of the female) with their perverse realization in the post-industrial landscape".
} 


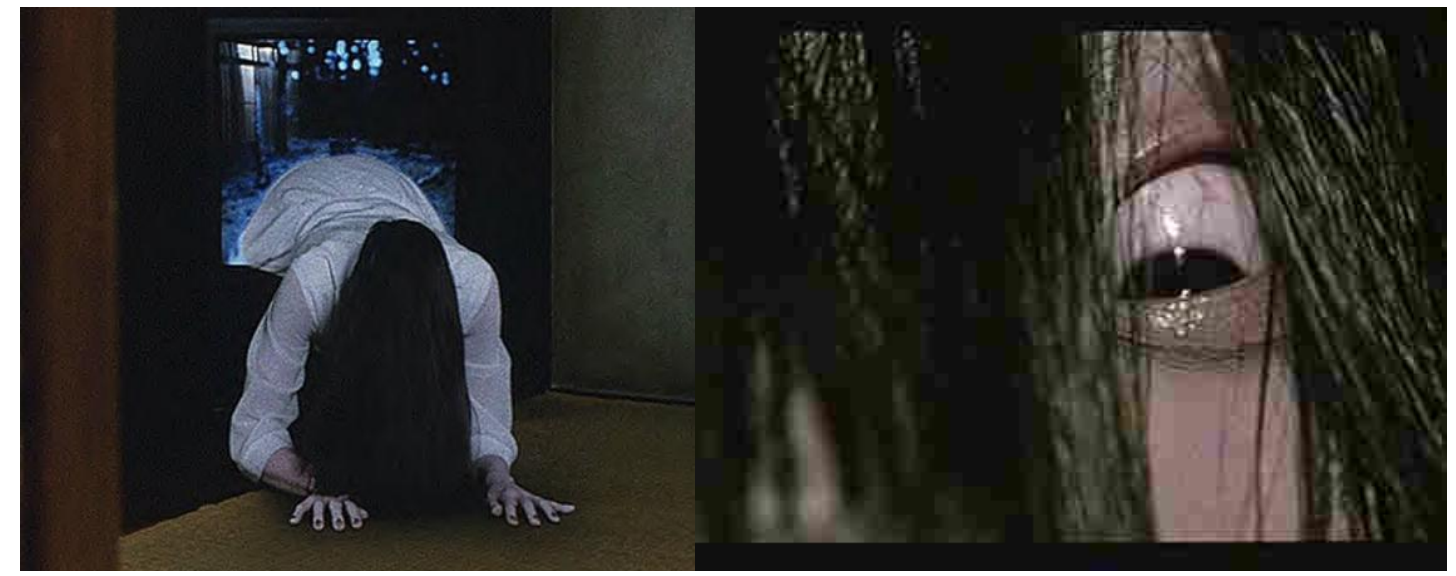

Figs. 1 e 2: Sadako, o fantasma vingativo de Ringu.

Nesta cena, o rapaz morre (literalmente) de medo ao ver Sadako sair transfigurada de dentro de um aparelho de televisão e arrastar-se em sua direção. Tudo começa quando, ao fazer suas anotações em uma escrivaninha, ele ouve sons vindos do aparelho de TV, que se encontra atrás dele, num cômodo contíguo. Ele se vira para trás e percebe na tela a imagem de um poço em plano geral, que é a última a aparecer no vídeo de Sadako. Intrigado, ele se dirige até o aparelho, e vê Sadako sair do poço em direção à câmera. O telefone toca, ele não atende, mas se afasta da televisão. Sadako continua com seu andar deformado em direção ao que pensamos ser a câmera, mas na verdade trata-se da tela da televisão, que ela atravessa, primeiro com a cabeça, e depois com o corpo inteiro (Fig 1), coberto em parte pelos longos cabelos pretos, que escondem completamente seu rosto. Podemos observar suas mãos ensanguentadas sem as unhas (perdidas provavelmente em tentativas de escalar o poço), os dedos deformados (pela mesma razão), a magreza, o caminhar alquebrado. Takayama corre pelo aposento, encosta-se na janela, tenta fugir de Sadako, até cair no chão. Ela segue impassível em direção a ele, até que mostra, por trás dos cabelos, seu olho gigante e aberto, matando Takayama - aparentemente, de susto.

A saída de Sadako de dentro da TV, aproximando-se tanto de sua vítima quanto do público, tornou-se assustadora por várias razões. Em primeiro lugar, pelo seu fator-surpresa no enredo do filme, pois, até aquele momento, tanto os personagens quanto os espectadores haviam sido levados a acreditar que a maldição de Sadako 
estava destruída. Em segundo lugar, trata-se da única vez em que assistimos a um "ataque" de Sadako a suas vítimas, pois, até aquele momento, tínhamos acesso apenas ao vídeo fantasmagórico e às suas consequências. Um terceiro motivo para o susto provocado pela cena está em sua própria construção, de intenso suspense em torno de um personagem que se encontra sozinho em casa, à noite, junto a quem assistimos, impotentes e paralisados, ao espetáculo tétrico protagonizado por Sadako. Outro motivo de impacto também parece estar no fato de que vemos sair de dentro da TV não um espectro, mas um corpo físico (Fig. 1) que se move de maneira monstruosa - muito semelhante, como vimos, a uma performance kabuki, sobretudo pelo olhar intenso e “esbugalhado" de Sadako (Fig. 2). Essa saída de um corpo físico de dentro da televisão, ainda que tenha antecedentes cinematográficos importantes ${ }^{15}$ (entre os quais Videodrome - A síndrome do vídeo, de David Cronenberg, 1982), transforma-se aqui num amálgama teatral, cinematográfico e televisivo que teve grande poder de atração para o público. Nesse sentido, Collette Bailmain, ao afirmar que a cultura japonesa tem uma "crença na materialidade dos fantasmas que a diferencia das concepções ocidentais" (2008: ix), parece oferecer uma chave possível para a compreensão do interesse gerado pela figura de Sadako fora do Japão.

Mas é a análise de Diane Arnaud que parece resumir melhor o poder de atração da aparição de Sadako. Para ela, nesta cena, como em outras do Kaidan-eiga contemporâneo, a encenação da aparição dos fantasmas coloca suas vítimas em posição semelhante à de espectadores em estado de choque, face a face com um espectro - o que, segundo ela, remete diretamente a um dispositivo teatral que chama de "atração fantasma" ("l'attraction fantôme") (2010: 121). Ela prossegue sua discussão buscando o conceito de atração de Eisenstein recuperado por Gaudreault e Gunning, que consiste na "autonomia do espetáculo em relação à narração, o que gera uma emoção-choque dada pela performance física" (Id. Ibid). Na mesma linha de Hand, a autora relaciona essas atrações fantasmas do cinema japonês recente à tradição teatral nacional de aparições espectrais do teatro Kabuki, e em particular às técnicas do keren e do mie (Ibid: 123).

É claro que essa ideia de atração fantasma herdada do teatro não se traduz, nesta cena do filme, em algo que se poderia chamar de "teatro filmado", no sentido de

${ }^{15}$ Sobre isso, Cf. SUPPIA, 2005. 
uma câmera postada frontalmente à ação, em planos gerais, relativamente fixos e com longa duração. Na verdade, o que ocorre é bem diferente disso: em 36 planos divididos em dois minutos e 42 segundos de duração, temos apenas seis planos gerais, enquanto os outros podem ser considerados médios ou close-ups, sendo que o extreme-close-up do olho de Sadako (Fig. 02) marca o clímax. A duração dos planos também é curta (em média, 4,5 segundos), o que leva à fragmentação do espaço, compensada por alguns movimentos de câmera que acompanham Takayama, primeiro aproximando-se da televisão, e depois distanciando-se dela e do espírito que sai em sua direção. Além disso, a sequência é montada num esquema de contracampos entre Takayama e o aparelho de televisão, e depois entre o jovem e o espírito de Sadako, o que mais uma vez contraria a ideia tradicional de teatro filmado.

Mas, ainda assim, pode-se perceber a herança do espetáculo teatral, e em vários sentidos. Em primeiro lugar, porque o uso do aparelho de televisão como primeira mediação entre o personagem e o fantasma instaura inicialmente uma relação de espectatorialidade segura, pois trata-se apenas de uma imagem eletrônica, e espectral. Isso permite que Takayama se aproxime da TV, ajoelhando-se no tatame diante da tela com curiosidade. Já a saída do corpo físico de dentro do aparelho é que constitui a grande surpresa da cena, e nesse momento há um destaque evidente para a expressão corporal do fantasma, localizada principalmente nas técnicas do mie já mencionadas: o caminhar alquebrado e caracterizado por paradas dramáticas, o enrijecimento dos dedos e a abertura dos olhos. E, sobretudo, o efeito da aparição de Sadako é baseado diretamente no seu potencial de espetáculo, já que aqueles que a assistem parecem morrer de medo apenas por deparar-se com ela. No caso paradigmático desse filme, então, o poder mortal do espírito reside em sua performance.

Se o apelo do Kabuki está na exploração de emoções extremas e de choque, é justo dizer que mecanismos semelhantes se encontram em ação nos filmes de horror japoneses. Como nota McRoy, se certa estética da crueldade é característica do Kabuki, o filme de horror japonês contemporâneo joga o mesmo jogo, adaptando - como parece ser recorrente nessa cinematografia - suas formas tradicionais aos desafios do mundo contemporâneo em estruturas cuidadosamente desenvolvidas (Id. Ibid). Daí o caráter de atração desta cena, posicionada no ponto do "susto final" típico dos filmes de horror, mostrar-se tão consistente. 


\title{
Processos de mútua fertilização e novas perguntas
}

No ano de lançamento da versão hollywoodiana de $O$ Chamado, Steve Rose, crítico do jornal inglês The Guardian, sentenciava: "o horror Americano não teve novas ideias desde os slashers dos anos 1980." (Apud HANTKE, 2005: 54). Três anos depois de Rose, Christopher Sharret ainda afirmaria sobre o horror anglo-saxão:

\begin{abstract}
A era de ouro do cinema de horror anglo-saxão entrou em decadência, junto com várias das melhores aspirações políticas do cinema comercial, durante a era Reagan/Thatcher - e não por acaso, considerando o radical desafio que o horror faz à cultura dominante. (...) Desde sua gloriosa origem no cinema de Weimar, e então na Universal, poucos gêneros foram tão profícuos quanto o horror em questionar noções como a da alteridade monstruosa, a natureza da família e do senso comum. (SHARRETT, 2005: ix, Tradução. $\left.\operatorname{nossa}^{16}\right)$.
\end{abstract}

Para embasar sua observação, Sharrett citava obras hoje clássicas do gênero como Psicose (Psycho, Hitchcock, EUA, 1960), Despertar dos Mortos (Dawn of the Dead, George Romero, EUA, 1978) e Quadrilha de Sádicos (The hills have eyes, Wes Craven, EUA, 1978), afirmando que estas não teriam sido igualadas em relevância após os anos 1980, e defendendo a ideia de que as novas esperanças para o gênero estariam nos filmes de horror japoneses que não paravam de chegar (Ibid: xii).

Além dos remakes $^{17}$ que procuraram adequar os padrões japoneses aos modelos clássicos convencionais, o mais próximo de uma resposta ocidental aos fantasmas vingativos que assombraram as telas no começo dos anos 2000 foi um grande número de filmes espíritas de horror, que adotaram as crenças ocidentais surgidas no século XIX voltadas à possibilidade de contato entre o nosso mundo e o dos espíritos desencarnados. Porém, a materialidade dos fantasmas japoneses, já descrita por Bailman, traz com ela uma noção de coexistência dos mundos dos vivos e dos mortos

\footnotetext{
${ }^{16}$ No original: "The golden age of the american and british horror cinema faded, with many of the best political aspirations of commercial film, during the Reagan/Thatcher era, a not coincidental occurrence considering the many radical challenges the horror film's impulses made to dominant culture. (...) Since its glorious inception first in the Weimar cinema, then at Universal Studios, few genres have been as blunt in questioning the notion of the monstrous Other, the nature of the family and other elements of received social wisdom as the horror film."

${ }^{17}$ Este assunto foi tema de pesquisa realizada por Rogério Ferraraz entre 2006 e 2007 junto à Universidade Anhembi Morumbi. Uma amostra desse estudo pode ser vista no artigo "Em sete dias, você será refeito: a adaptação de Ringu - o chamado pelo remake hollywoodiano" (FERRARAZ, 2006).
} 
que parece mais ameaçadora do que a descrita nos filmes espíritas - que se aproximam muito frequentemente do melodrama, apresentando a possibilidade de apaziguamento dos espíritos atormentados através de processos de negociação com os vivos. Entre esses filmes, temos sucessos como O Sexto Sentido (The Sixth Sense, M. Night Shyamalan, 1999), Os Outros (The Others, Alejandro Almenabar, 2001), Vozes do Além (White Noise, Geoffrey Sax, 2004), O Despertar (The Awakening, Nick Murphy, 2011) e A Mulher de Preto (Woman in Black, James Watkins, 2012), entre dezenas de outros.

Enfim, são várias as questões que restam por responder. Com o presente artigo, buscamos trazer algumas reflexões a partir de uma revisão teórica sobre os aspectos atracionais do horror japonês. Mas ainda há o que discutir, por exemplo, quanto aos efeitos técnicos, estéticos e temáticos da transposição de estratégias desses filmes para os remakes feitos para o grande mercado internacional. Também é importante investigar até que ponto a participação desses novos exemplos do cinema de horror oriental e sua aceitação pelo público acabaram influenciando a volta da produção em larga escala de filmes do gênero horror em várias partes do mundo. Dez anos depois do lançamento mundial da versão americana de $O$ Chamado, o fenômeno de reprodução sem fim iniciado pelo vídeo de Sadako ainda parece estar em vigor, o que confirma a impressão da centralidade da obra de Nakata para o horror contemporâneo.

\section{Referências bibliográficas}

ARNAUD, Diane. "L'attraction fantôme dans le cinema d'horreur japonais contemporain". In: In: Revue d'etudes cinematographiques. Vol 20, n. 2-3, Qébec, Université de Montreal, 2010, p. 120 a 141.

BALMAIN, Collete. Introduction do japanese horror film. Edinburgh Universyity Press. 2008.

BÉGIN, Richard; GUIDO, Laurent. "Présentation". Revue d'etudes cinematographiques. Vol 20, n. 2-3, Qébec, Université de Montreal, 2010, p. 07 a 11.

CÁNEPA, Laura. "O filme da Edison Co. e a releitura cinematográfica do Frankenstein de Mary Shelley". In: SANTANA, Gelson (org). Comunicação, Cinema, Audiovisual. São Paulo: Alameda, 2008, 217 a 224.

CARROLL, Noël. A filosofia do horror ou Paradoxos do coração. Campinas: Papirus, 1999.

CLOVER, Carol. Men, women, and chain saws: gender in modern horror film. Princeton University Press, 1993. 
FELINTO, Erick. "Imagens que matam: o imaginário do pânico midiático no novo cinema oriental”. Revista Ícone, Pernambuco, V.2, n. 9, dez. 2006, p. 11-28.

FERRARAZ, Rogério. "Em sete dias, você será refeito: a adaptação de Ringu - o chamado pelo remake hollywoodiano". In: XXIX CONGRESSO BRASILEIRO DE CIÊNCIAS DA COMUNICAÇÃO. Brasília: UnB, 2006. Anais...São Paulo: Intercom, 2006. CD-ROM

. "A trajetória do Frankenstein cinematográfico". In: SANTANA, Gelson (org). Comunicação, Cinema, Audiovisual. São Paulo: Alameda, 2008, 205 a 216.

GAUDREAULT, Andre. "Narration et monstration au cinéma", Hars Cadre, Cinenarrable 2, 1984, Paris VIII, pp.87-98.

GUIDO, Laurent. "De l'opéra de l'oeil aux films à sensation: musique et théâtralité aux sources de l'horreur cinématographique." In: Revue d'etudes cinematographiques. Vol 20, n. 2-3, Qébec, Université de Montreal, 2010, p. 13 a 40.

GUNNING, Tom. "The Cinema of Attractions: Early Films, its Spectator and the AvantGarde”. Wide Angle, V. 8, n. 3/4, Baltimore, John Hopkins University Press, 1986.

HANDA, Francisco. "Kabuki - Uma forma de teatro popular estilizada". In: Cultura Japonesa. Disponível em: http://www.culturajaponesa.com.br/htm/kabuki.html. Último acesso: Set. 20, 2012.

HAND, Richard J. Aesthetics of cruelty: Traditional Japanese Theatre and the Horror Film. In: McROY, Jay (org). Japanese horror cinema. Honolulu: University of Hawai Press, 2005, p. $18-29$.

HUMPHRIES, Reynold. The american horror film: an introduction. Edinburgh: Edinburgh UP, 2002. $224 \mathrm{p}$.

JANKOVICH, Mark. "Introduction". In: JANKOVICH, Mark (org). Horror, The Film Reader. Londres: Routledge, 2002.

KALAT, David. J-Horror: the definitive guide to The Ring, The Grudge and beyond. Nova Iorque: Vertical, 2007.

LENNE, Gérard. El cine fantástico y sus mitologías. Barcelona: Anagrama, 1974.

McROY, Jay (org). Japanese horror cinema. Honolulu: University of Hawai Press, 2005.

MORGAN, Jack. The biology of horror: gothic literature and film. Southern Illinoys Press, 2002. $280 \mathrm{p}$.

NEALE, Steven. Genre and Hollywood. Londres: Routledge, 2000.

POWELL, Anna. Deleuze \& the horror film. Edinburgo: Edinburgh University Press, 2005.

SCONCE, Jeffrey. Haunted media: Electronic presence from Telegraphy to Television. Duke University Press: 2000.

SPADONI, Robert. "The old dark house and the Space of Attraction". In: Revue d'etudes cinematographiques. Vol 20, n. 2-3, Qébec, Université de Montreal, 2010, p. 65 a 96. 
SUPPIA, Alfredo Luiz Paes de Oliveira. "Screened Panic: cinema fantástico ou de ficção científica e a ameaça do vídeo - os casos Videodrome, Akumulator 1 e $O$ Chamado". In: CATANI, Afrânio Mendes, GARCIA, Wilton e FABRIS, Mariarosaria (org.). Estudos Socine de Cinema: ano VI. SP: Nojosa, 2005. p. 69-77.

WILLIAMS, L. "Film bodies: gender, genre, and excess". In: R. STAM; T. MILLER (Orgs.). Film and theory: an anthology. Oxford: Blackwell, 2000, p. 207-221.

WOOD, Robin; LIPP, Richard. The American Nightmare: Essays on the Horror Film. University of Michigan Press, 1979. 